\title{
Optimization of Leaf-disk Transformation and High Frequency Regeneration of
} Nicotianan benthamiana

Zhao Xianlei *, Dong Zijian ", Xie Xingbang, Zhang Zhuang, Wu Yangyang, Zhang Qianqian, Sun Wenwen, Du Xiuju, Cao Xuesong, $\mathrm{Hu}$ Qüan'an $\unrhd$

Liaocheng University, College of Life Sciences, Liaocheng, 252000, P.R. China

* The authors contribute equally to this work

$\nabla$ Corresponding author email: huquanan@lcu.edu.cn

Plant Gene and Trait, 2020, Vol.11, No.12 doi: 10.5376/pgt.2020.11.0012

Received: 21 Dec, 2020

Accepted: 23 Dec, 2020

Published: 27 Dec, 2020

Copyright (c) 2020 Zhao et al., This article was first published in Molecular Plant Breeding in Chinese, and here was authorized to translate and publish the paper in English under the terms of Creative Commons Attribution License, which permits unrestricted use, distribution, and reproduction in any medium, provided the original work is properly cited.

Preferred citation for this article:

Zhao X.L., Dong Z.J., Xie X.B., Zhang Z., Wu Y.Y., Zhang Q.Q., and Sun W.W., 2020, Optimization of leaf-disk transformation and high frequency regeneration of Nicotianan benthamiana, Plant Gene and Trait, 11(12): 1-10 (doi: 10.5376/pgt.2020.11.0012)

\begin{abstract}
Nicotianan benthamiana is a close relative of Nicotiana Tabacum. It's widely used in studies of "Plant-Pathogen interactions". Leaf-disk plant transformation method is widely used in plant molecular biology. In this research, we compared different parameters of different steps of Nicotiana benthamiana leaf-disk transformation procedure. We found co-cultivation at $18^{\circ} \mathrm{C}$, balances the transformation frequency and late on selection better than the commonly used $25^{\circ} \mathrm{C}$. Upon this pre-condition, we optimized parameters of the other steps of leaf-disk transformation of Nicotianan benthamiana. In the meanwhile, the research optimized the concentration of $\mathrm{AgNO}_{3}$ and Phytagel of regeneration medium, in the context of bud's induction. The research found that adding $4.3 \mathrm{mg} / \mathrm{L} \mathrm{AgNO}_{3}$ and $8.8 \mathrm{~g} / \mathrm{L}$ phytagel in the medium, gives the highest buds induction rate.
\end{abstract}

Keywords Nicotiana benthamiana; Buds induction; Silver nitrate; Phytagel; Genetic transformation

Nicotiana benthamiana has the characteristics of small plant, susceptible to disease with relatively short life cycle. As a model plant of "plant-pathogen interactions", Nicotiana benthamiana has been widely used in plant molecular biology researches. Recently, researches using Nicotiana benthamiana as materials are increasing rapidly. However, conditions and parameters used in the leaf-disk transformation were mostly optimized for Nicotiana Tobacum. For example, the co-cultivation time is $2 \sim 3$ days; the bacterium concentration for co-cultivation is mostly between $O D_{600}$ value at around $0.2 \sim 0.4$; the co-cultivation temperature is mostly controlled at $22^{\circ} \mathrm{C} \sim 28^{\circ} \mathrm{C}$ (Wang et al., 2018).

$\mathrm{AgNO}_{3}$ is an inhibitor of ethylene synthase ACC (Eapen and George, 1997; Nail and Chand, 2003), which is widely used in plant tissue culture to improve regeneration efficiency. Pestana (1999) used $\mathrm{AgNO}_{3}$ to induce peanut callus budding, it was also used in cowpea (Mookkan and Andy, 2014), maize (Du et al., 2008), Chinese cabbage (Du et al., 2000), strawberry (Qin et al., 2006), cucumber (Cao et al., 2001), Rushan, rape, Brassica napus, black cabbage (Eapen and George, 1997). On the other hand, the hardness of plant medium had a significant effect on plant regeneration and differentiation (Wang and Zhou, 2000; Zhai et al., 2010; Zhao et al., 2007). Our previous studies also found that using high concentration of phytagel in tissue culture of N.benthamiana, significantly increasing the frequency of regeneration.

The study optimized the conditions of leaf-disc transformation of $N$. benthamian. The effects of different concentrations of $\mathrm{AgNO}_{3}$ and different concentrations of phytagel (Affecting the hardness of the medium) on the regeneration of $N$. benthamiana were studied, respectively.

\section{Results}

\subsection{Optimizing of the conditions of N.benthamiana leaf-disc transformation}

1.1.1 Effects of co-cultivation temperature on transformation efficiency

pCambia1305.1 (in GV3101) was used to treat 16 explants at $18^{\circ} \mathrm{C}, 21^{\circ} \mathrm{C}, 25^{\circ} \mathrm{C}$ and $28^{\circ} \mathrm{C}$ for three times. After 3 
days of co-cultivation, GUS staining was performed with X-gluc

Results showed that GUS staining was better at $18 \sim 25^{\circ} \mathrm{C}$ (Figure 1a; Figure 1b; Figure 1c), indicating that the transformation efficiency was high at these temperatures. When the temperature was up to $28{ }^{\circ} \mathrm{C}$ (Figure 1d), GUS staining was obviously poor, indicates at this temperature, the transformation frequency was low.

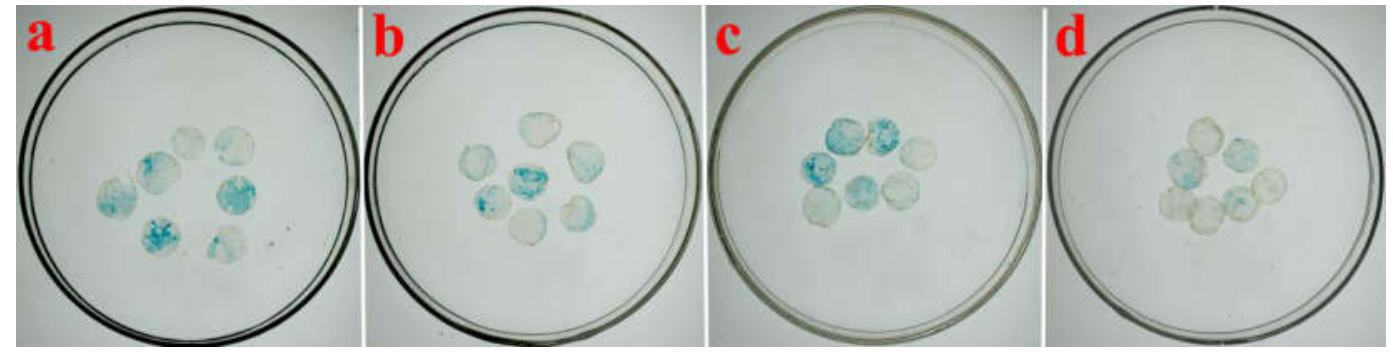

Figure 1 GUS staining after co-cultivation at different temperatures

Note: a d: Gus staining at $18^{\circ} \mathrm{C}, 21^{\circ} \mathrm{C}, 25^{\circ} \mathrm{C}$ and $28^{\circ} \mathrm{C} 3$ days after co-cultivation

According to statistics, when the co-cultivation temperature was $18^{\circ} \mathrm{C}$ and $21^{\circ} \mathrm{C}$, the transformation rate was the highest, which was $47.92 \%$; when the temperature was further increased, the transformation rate was significantly reduced (Figure 2), and the genetic transformation rate was significantly reduced at $25^{\circ} \mathrm{C}$ and $28^{\circ} \mathrm{C}$, which were $31.25 \%$ and $18.75 \%$, respectively.

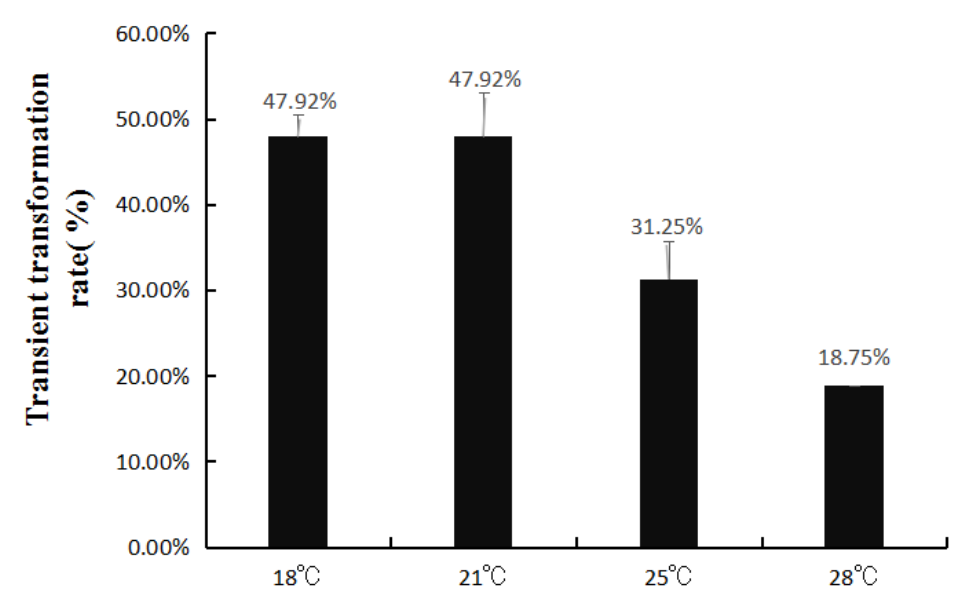

Figure 2 Influence of different co-cultivation temperatures on transient transformation rate

The optimum growth temperature of Agrobacterium tumefaciens is about $28^{\circ} \mathrm{C}$. However, the transformation efficiency is the highest at $18^{\circ} \mathrm{C} \sim 25^{\circ} \mathrm{C}$. After co-cultivation, it is necessary to enter the process of antimicrobial screening; the overgrowth of Agrobacterium is often one of the difficulties in the process of leaf-disc transformation. The results showed that the transformation efficiency of co-cultivation at $18^{\circ} \mathrm{C}$ was similar to that at $25^{\circ} \mathrm{C}$. Considering that the growth rate of Agrobacterium tumefaciens significantly slowed down at $18^{\circ} \mathrm{C}$, which was more conducive to the inhibition of Agrobacterium in the following selection process, we thus chose this co-cultivation temperature, $18^{\circ} \mathrm{C}$, as the basis to optimize the other related genetic transformation conditions.

\subsubsection{Effects of different co-cultivation times on leaf-disc transformation efficiency}

Through observing GUS staining of N.benthamiana explants after 1 day, 2days and 3days of co-cultivation, we found that the longer the co-cultivation time, the better the GUS staining, and the better the number and quality of infected leaves were (Figure 3). When the co-cultivation time increased to 3 days, there were more spot staining areas and more leaves got stained (Figure 3c), which indicated that the infection rate of these explants was high; however, when the co-cultivation time was as short as 1 day, there was almost no staining (Figure 4). 
Plant Gene and Trait 2020, Vol.11, No.12, 1-10

http://genbreedpublisher.com/index.php/pgt

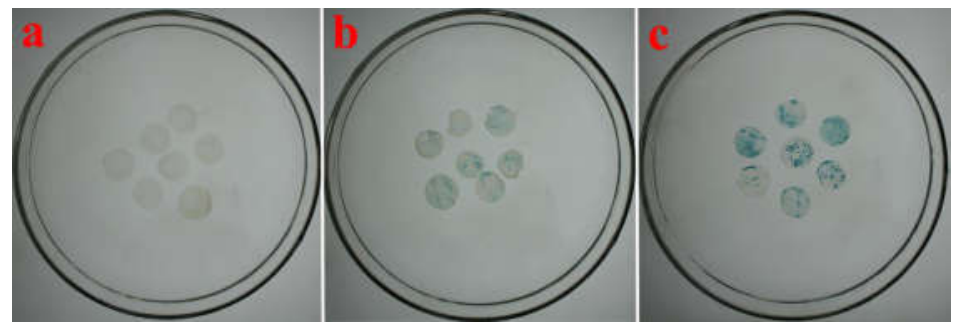

Figure 3 GUS staining of co-culticvation after $1 \mathrm{~d}, 2 \mathrm{~d}$ and $3 \mathrm{~d}$ at $18{ }^{\circ} \mathrm{C}$

Note: The order of $\mathrm{a} \sim \mathrm{c}$ is $1 \mathrm{~d}, 2 \mathrm{~d}$ and $3 \mathrm{~d}$ GUS staining

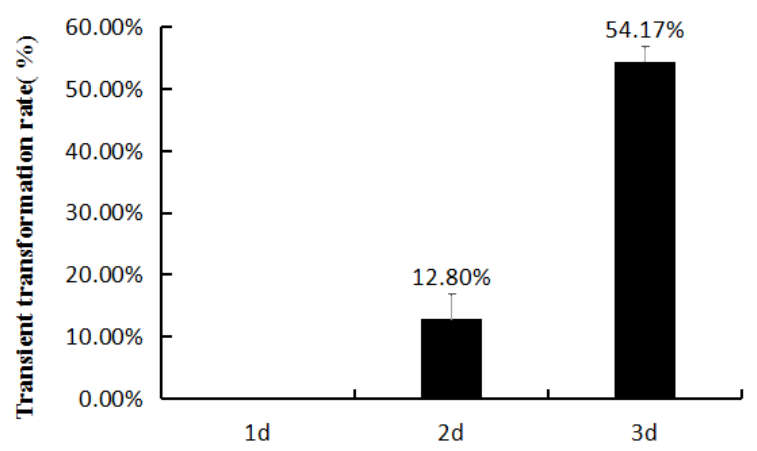

Figure 4 Influence of different co-cultivation time on transient transformation rate

\subsubsection{Effects of different pre-cultivation times on transformation rate}

Under the condition of 3 days co-cultivation at $18^{\circ} \mathrm{C}$, Effects of different pre-cultivation times, $1 \mathrm{~d}, 2 \mathrm{~d}$ and $3 \mathrm{~d}$, of N.benthamiana leaf disk transformation rates were compared. Each treatment had 10 16 leaf discs and was repeated three times.

As the results showed, the staining effect was better when the pre-cultivation times were 1 day and 2 days, but the staining quantity was relatively less in the later (Figure 5b, Figure 6); when the pre-cultivation time was 3 days, the staining quantity was significantly reduced (Figure 5c, Figure 6).

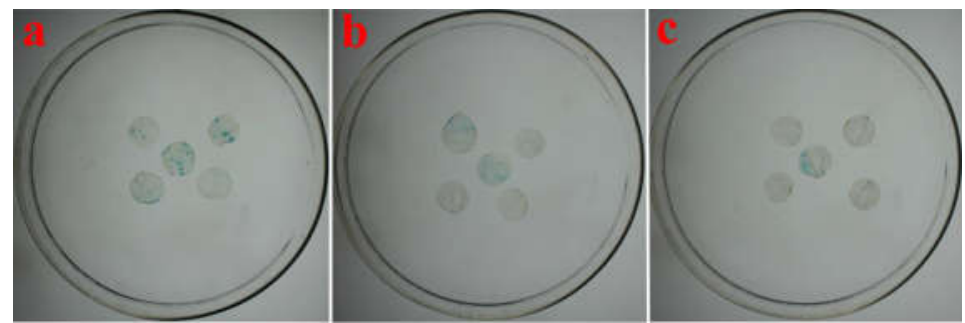

Figure 5 GUS-Staining after Different Pre-cultivation time

Note: a c: GUS-staining of pre-cultured for 1,2 and 3 days at $18{ }^{\circ} \mathrm{C}$

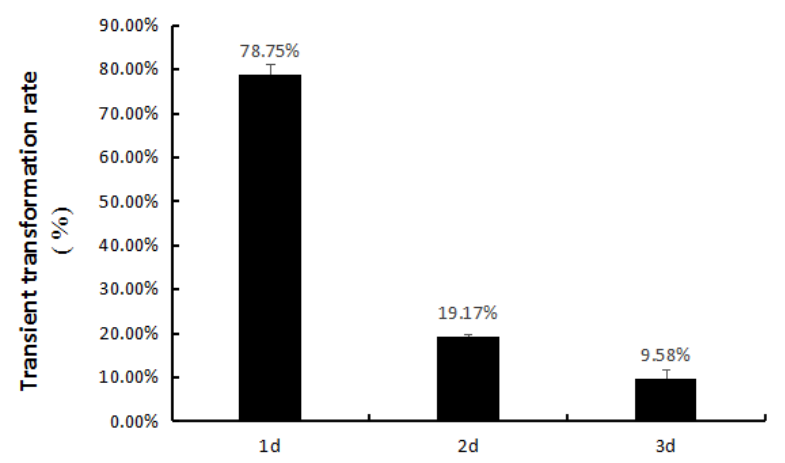

Figure 6 Conversion Rate of Different Pre-culture Days

Note: The transformation rate of $0,1 \mathrm{~d}, 2 \mathrm{~d}$ and $3 \mathrm{~d}$ treatment respectively 
Plant Gene and Trait 2020, Vol.11, No.12, 1-10

http://genbreedpublisher.com/index.php/pgt

1.1.4 Effects of different concentrations of agrobacterium on transformation rate

After optimized the co-cultivation temperature, co-cultivation time and pre-cultivation time, we studied the effect of different concentrations of agrobacterium on the transformation rate. Agrobacterium tumefaciens GV3101-pCAMBIA1305.1 was cultured at $28^{\circ} \mathrm{C}$ to $O D_{600} \approx 0.5$, spin at $5000 \mathrm{r} / \mathrm{min}$ to pellet bacterium, afterwards, re-suspend with sterilized liquid MS medium to $O D_{600} \approx 0.3, O D_{600} \approx 0.6, O D_{600} \approx 1.0$, respectively, for ready infection. The leaf discs were soaked in the ready bacterium solutions for $5 \sim 7$ minutes, and then send to co-cultivation at $18^{\circ} \mathrm{C}$ for 3 days. 16 leaves were randomly selected for GUS staining and these results were repeated for three times.

Staining results indicated that, when $O D_{600}=0.321$, the leaves were well stained, but most of them were dot blue spots, most of the leaves gave positive staining (Figure 7a); when $O D_{600}=0.639$ and $O D_{600}=1.043$, the staining of leaves was obviously better, and some leaves showed larger staining area, however, there was no significant difference between the two treatments (Figure 7b; Figure 7c).

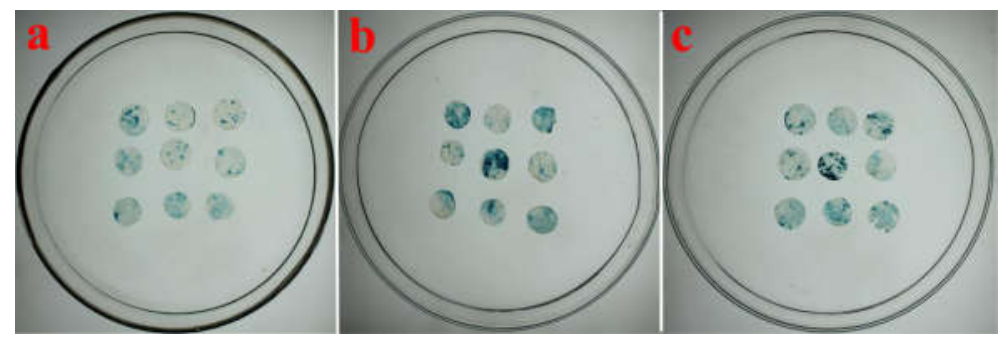

Figure 7 Influence of different concentrations of agrobacterium on transient transformation rate Note: $\mathrm{a} \sim \mathrm{c}$ : GUS staining when $O D_{600}=0.321, O D_{600}=0.639$ and $O D_{600}=1.043$

\subsection{Effects of $\mathrm{AgNO}_{3}$ concentration and phytagel concentration on induced buds' differentiation}

\subsection{1 $\mathrm{AgNO}_{3}$ benefits bud induction in $N$. benthamiana}

The results indicate certain concentration of $\mathrm{AgNO}_{3}$ benefits N.benthamiana buds induction as well as regeneration. When the concentration of $\mathrm{AgNO}_{3}$ was $1.5 \mathrm{mg} / \mathrm{L} \sim 4.5 \mathrm{mg} / \mathrm{L}$, the buds was healthier than the control treatment, while the browning of callus was obvious at $6 \mathrm{mg} / \mathrm{L}$. Nonetheless, $4.5 \mathrm{mg} / \mathrm{L} \mathrm{AgNO}$ gives best results in the terms of buds' induction (Figure 8; Figure 9).

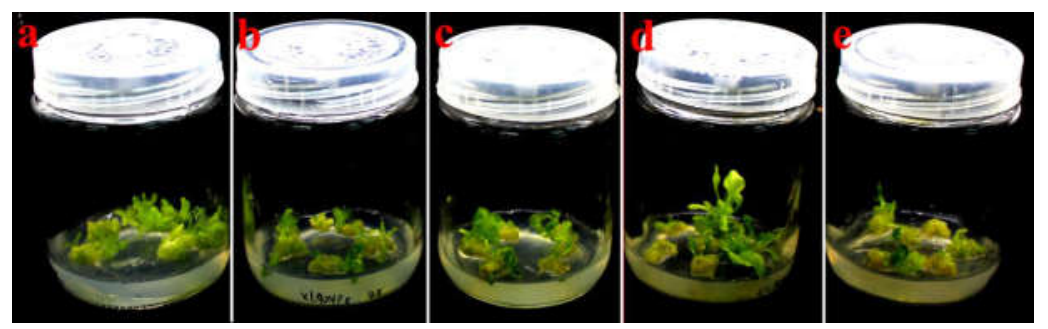

Figure 8 Bud induction at different $\mathrm{AgNO}_{3}$ concentrations

Note: $\mathrm{AgNO}_{3}$ Conc. A: 0; b: $1.5 \mathrm{mg} / \mathrm{L}$; c: $3 \mathrm{mg} / \mathrm{L} ; \mathrm{d}: 4.5 \mathrm{mg} / \mathrm{L} ;$ e: $6 \mathrm{mg} / \mathrm{L}$

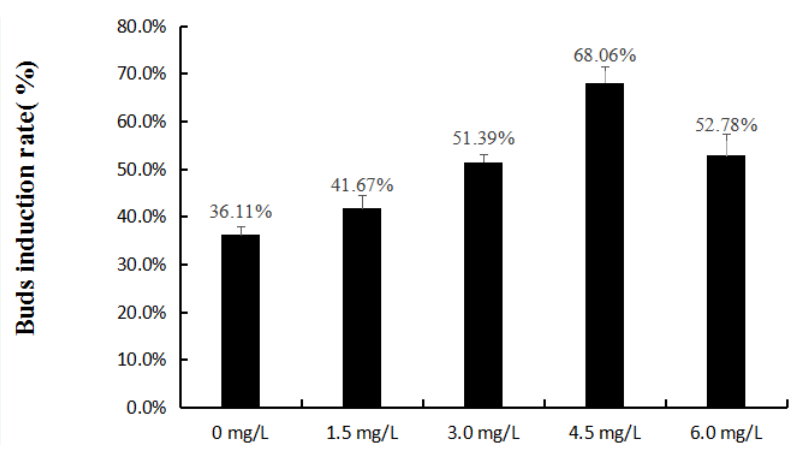

Figure 9 Buds induction at different $\mathrm{AgNO}_{3}$ concentrations

Note: Germination rate of $0 \sim 6 \mathrm{mg} / \mathrm{L} \mathrm{AgNO}_{3}$ 
Plant Gene and Trait 2020, Vol.11, No.12, 1-10

http://genbreedpublisher.com/index.php/pgt

\subsubsection{High concentrations of phytagel benefits buds induction of N.benthamiana}

In this experiment, we found that, when the phytagel concentration is of $5 \mathrm{~g} / \mathrm{L}$ (Figure 10a), the medium is relatively soft and the surface water is relatively more. The callus was trapped in the medium with heavy water content, and the bud induction rate was lower. With the increase of the phytagel concentration, the number of callus increased significantly. When the phytagel concentration reaches $9 \mathrm{~g} / \mathrm{L}$ (Figure 10c), the medium is harder, while callus can still be attached to the medium surface. Water contents of the callus is obviously reduced, and the bud differentiation rate is much higher. When the phytagel concentration reaches $10 \mathrm{~g} / \mathrm{L}$ (Figure 10d), the medium is too hard to adhere the callus, and thus cannot be used in practical. Buds induction rates were indicated in Figure 11.

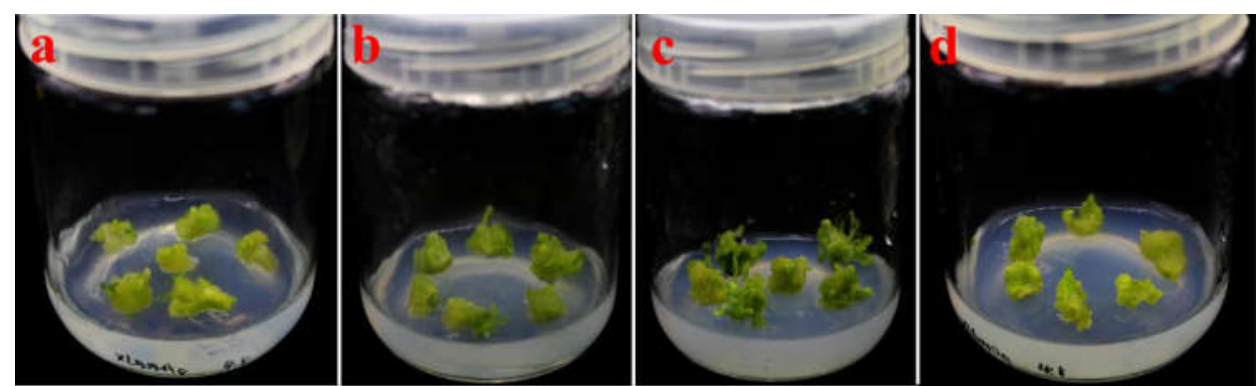

Figure 10 Influence of phytagel concentrations on Buds induction

Note: a d: 5 g/L; 7 g/L; 9 g/L and 10 g/L phytagel

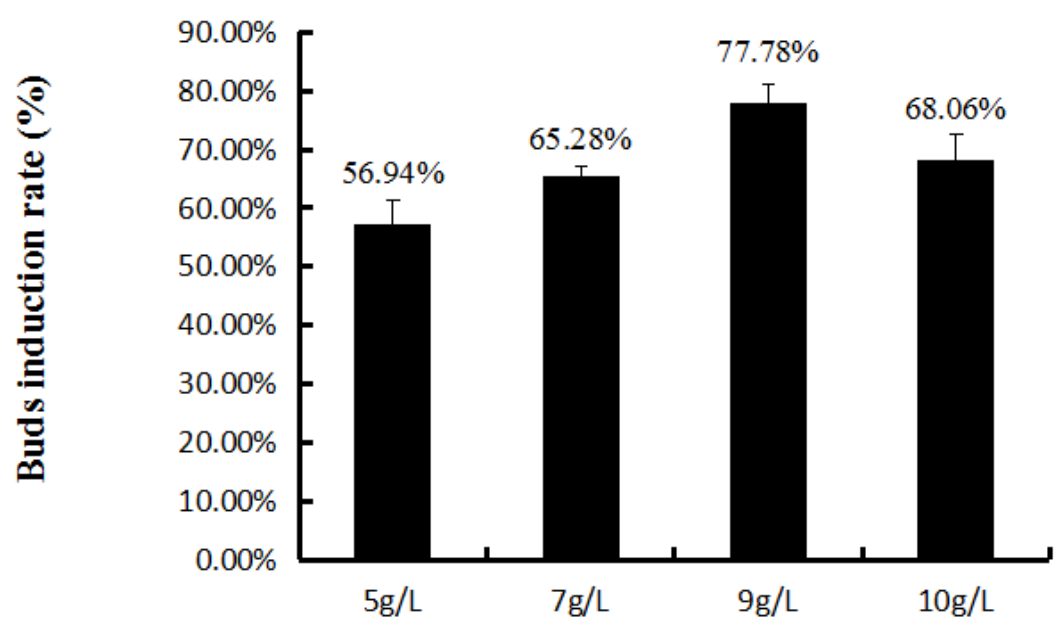

Figure 11 Bud induction rate of different phytagel concentrations

1.2.3 Response surface test to find the best combination of different $\mathrm{AgNO}_{3}$ and Phytagel concentrations.

In the single factor experiment, the highest buds induction rate was reached when using $4.5 \mathrm{mg} / \mathrm{L} \mathrm{AgNO}$ and 9 $\mathrm{g} / \mathrm{L}$ phytagel, respectively. Thus, in this design as indicated in Table 1 , we took $4.5 \mathrm{mg} / \mathrm{L} \mathrm{AgNO}_{3}$ and $9 \mathrm{~g} / \mathrm{L}$ phytagel as the combination center, followed by employing Design Expert10 software to select CCD model and conduct two factor response surface design experiment.

According to the CCD model in Design Expert 10 software, experimental groups was designed, with 10 bottles in each group and 6 pieces of calli in each bottle (Table 2).

Table 1 Factors of response surface test design

\begin{tabular}{lll}
\hline Level & $\mathrm{AgNO}_{3}$ concentration $(\mathrm{mg} / \mathrm{L})$ & Phytagel concentration $(\mathrm{g} / \mathrm{L})$ \\
\hline-1.414 & 2.4 & 7.6 \\
-1 & 3 & 8 \\
0 & 4.5 & 9 \\
1 & 6 & 10 \\
1.414 & 6.6 & 10.4 \\
\hline
\end{tabular}


Plant Gene and Trait 2020, Vol.11, No.12, 1-10

http://genbreedpublisher.com/index.php/pgt

Table 2 Response surface analysis program and response

\begin{tabular}{llll}
\hline Serial number & $\mathrm{A} \mathrm{AgNO}_{3}(\mathrm{mg} / \mathrm{L})$ & B Phytagel $(\mathrm{g} / \mathrm{L})$ & YBuds induction rate $(\%)$ \\
\hline 1 & 6.6 & 9 & 58.33 \\
2 & 6 & 8 & 78.33 \\
3 & 3 & 8 & 71.67 \\
4 & 4.5 & 9 & 85 \\
5 & 4.5 & 9 & 88.33 \\
6 & 4.5 & 10.4 & 70 \\
7 & 4.5 & 9 & 90 \\
8 & 2.4 & 9 & 70 \\
9 & 6 & 10 & 53.33 \\
10 & 4.5 & 9 & 85 \\
11 & 4.5 & 9 & 86.67 \\
12 & 4.5 & 7.6 & 75 \\
13 & 3 & 10 & 75 \\
\hline
\end{tabular}

The corresponding response values of each group were counted. Multivariate linear regression was applied to the results of Table 2 by using Design expert 10 software. The two variable two equation of $\mathrm{AgNO}_{3}$ concentration (A) and phytagel concentration (B) as independent variables was obtained: $\mathrm{Y}=-7.22+0.84 \mathrm{~A}+1.43 \mathrm{~B}-0.05 \mathrm{AB}-$ $0.05 \mathrm{~A}^{2}-0.07 \mathrm{~B}^{2}$

In order to validate of the regression equation and further confirm the influence of various factors on tobacco budding rate, the regression model was analyzed by variance (Table 3 ).

Data told that the regression model is extremely significant $(p<0.0001)$, indicating that the establishment of the model is meaningful; the mismatch term $p=0.2404>0.05$, the difference is not significant, indicating that the model fitting degree is good. The composite correlation coefficient $r^{2}=0.9684$ and the correction coefficient of determination $\left(\mathrm{R}_{\mathrm{adj}}{ }^{2}\right)$ were 0.9458 , which indicate that there was a good fit between the actual value and the theoretical value of N.benthamiana buds induction rate, and the regression model could be used to analyze and predict the buds induction effect of N.benthamian (Table 3).

Table 3 Response surface method variance analysis

\begin{tabular}{lllllll}
\hline Source & Sum of squares & $\mathrm{df}$ & Mean aquares & $F$ value & $p$ value & Significance \\
\hline Model & 0.15 & 5 & 0.030 & 42.89 & $<0.0001$ & $* * *$ \\
$\mathrm{~A}-\mathrm{A}$ & 0.012 & 1 & 0.012 & 17.75 & 0.0040 & $* *$ \\
$\mathrm{~B}-\mathrm{B}$ & 0.010 & 1 & 0.010 & 14.77 & 0.0063 & $* *$ \\
$\mathrm{AB}$ & 0.020 & 1 & 0.020 & 28.72 & 0.0011 & $* *$ \\
$\mathrm{~A}^{2}$ & 0.086 & 1 & 0.086 & 122.73 & $<0.0001$ & $* * *$ \\
$\mathrm{~B}^{2}$ & 0.033 & 1 & 0.033 & 47.90 & 0.0002 & $* * *$ \\
Residual & 4.89 & 7 & 6.99 & & & \\
Lack of fit & 3.00 & 3 & 1.00 & 2.12 & 0.2404 & not significant \\
Pure error & 1.89 & 4 & 4.72 & & & \\
The total deviation & 0.15 & 12 & & & & \\
$r^{2}$ & & & & 0.9684 & & \\
$\mathrm{R}_{\mathrm{Adj}}{ }^{2}$ & & & & 0.9458 & & \\
\hline
\end{tabular}

The interaction between different concentrations of $\mathrm{AgNO}_{3}$ and phytagel was analyzed (Figure 12). Within the detection range, the response surface graph was a convex surface with the opening downward, which indicated that there was a maximum of the buds induction rate of N.benthamiana. From the contour line of 2 vs 2 interactions, it is clear that the interaction between two factors of $\mathrm{AgNO}_{3}$ concentration and phytagel concentration has significant effect on buds induction of N.benthamiana. Through Design Expert10 software 
Plant Gene and Trait 2020, Vol.11, No.12, 1-10

http://genbreedpublisher.com/index.php/pgt

analysis, the optimal parameters of N.benthamiana buds induction were $4.33 \mathrm{mg} / \mathrm{L} \mathrm{AgNO} 3$ combined with $8.8 \mathrm{~g} / \mathrm{L}$ phytagel. Under this condition, the theoretical value of buds induction rate of N.benthamiana was $87.58 \%$.
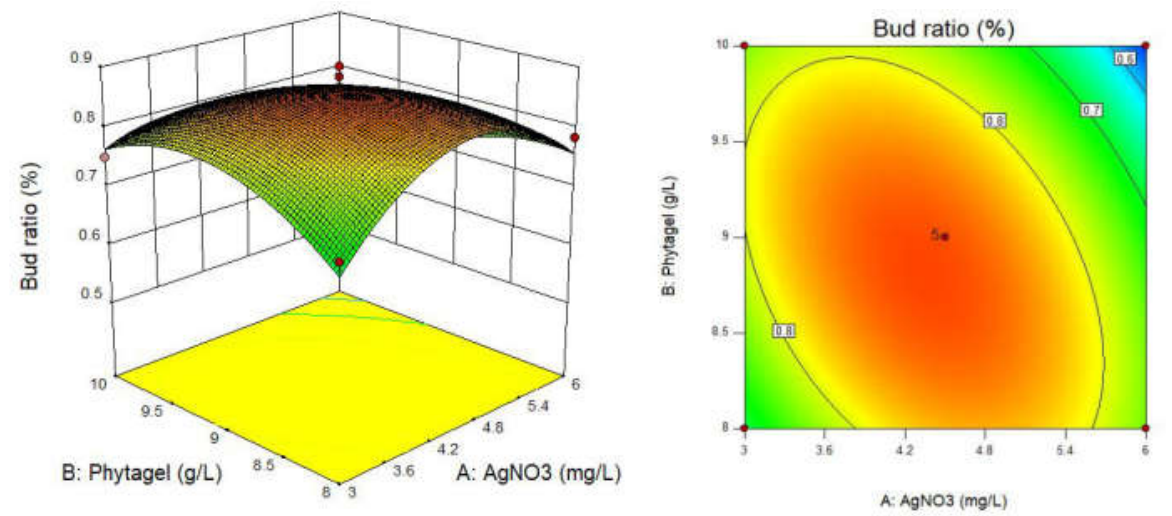

Figure 12 Response surface diagram of the interaction of two and two factors to tobacco budding rate

Note: Response surface and contour map of $\mathrm{AgNO}_{3}$ concentration and phytagel concentration with respect to buds induction rate

\subsubsection{Verification test}

According to results of above response surface experiment, we design the following verification experiments. Four groups of experiments were performed, with 5 bottles in each group and 6 pieces of calli in each bottle. After two weeks, bud's induction rate of each group was counted and calculated. The buds induction rate=the number of budding calli/the total number of calli * $100 \%$ (Table 4 ).

Table 4 Validation Test: Combination of $\mathrm{AgNO}_{3}$ and Phytagel Concentration

\begin{tabular}{lllll}
\hline & I & II & III & IV \\
\hline $\mathrm{AgNO}_{3}(\mathrm{mg} / \mathrm{L})$ & 0 & 4.3 & 0 & 4.3 \\
Phytagel $(\mathrm{g} / \mathrm{L})$ & 5 & 8.8 & 8.8 & 5 \\
\hline
\end{tabular}

According to the results of three parallel experiments, the buds induction rate histogram of each group was drawn (Figure 13).The verified buds induction rate of combination of $4.3 \mathrm{mg} / \mathrm{L} \mathrm{AgNO} 3$ and $8.8 \mathrm{~g} / \mathrm{L}$ phytagel is $85.19 \%$, which is very close to the theoretical value $87.58 \%$ (Figure 13). Thus, through the response surface test, we optimized the best condition of the two factors combination.

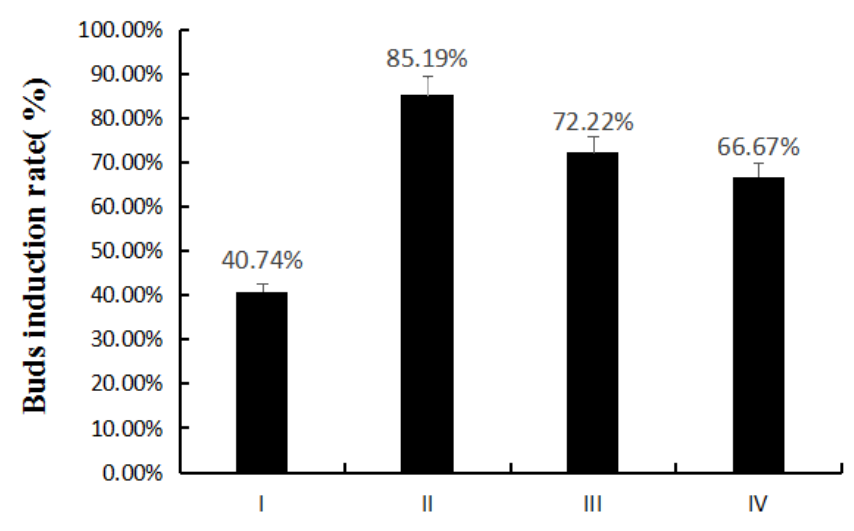

Figure 13 Germination rate of each group

Note: Sprouting rate of tobacco treated with four concentrations of $\mathrm{AgNO}_{3}$ and gellan gum

\subsection{The optimized process and parameters of N.benthamiana leaf disc transformation method}

Based on the results of the above experiments, the optimized brief process and parameters of N.benthamiana leaf disc transformation are as follows:

1) Three days in ahead of time, Agrobacterium tumefaciens was cultured by shaking at $28^{\circ} \mathrm{C}$. 
2) On the first day, healthy leaves of 40 60 days (After seed germination) sterile plants were selected and cut into leaf discs of $\sim 0.8 \mathrm{~cm} \times 0.8 \mathrm{~cm}$, and pre-cultivated for 1 day at $25^{\circ} \mathrm{C}$ on $\mathrm{MS}$ solid medium; meanwhile, Agrobacterium tumefaciens was sub-cultured.

3) On the second day, the agrobacterium culture is grown to $O D_{600} \approx 0.5$; the bacteria are then collected at $4^{\circ} \mathrm{C}, 5$ $000 \mathrm{r} / \mathrm{min}$ for $15 \mathrm{~min}$; and then the pellet is resuspended on MS liquid medium to $O D_{600} \approx 1$. The pre-cultivated leaves discs were immersed in the bacterium suspension for 3-5 minutes, the excess bacterial solution was sucked out with sterile filter paper.

4) Resulted leaf discs were placed on MS solid medium containing acetosyringone $(50 \mu \mathrm{M} \sim 100 \mu \mathrm{M})$ for co-cultivation at $18^{\circ} \mathrm{C}$ for 3 days;

5) After co-cultivation, the leaf discs were rinsed 2 3 times with sterile water (containing $500 \mathrm{mg} / \mathrm{L}$ Cefalothin Sodium), and then the leaf discs were transferred to selection medium (containing $4.3 \mathrm{mg} / \mathrm{L} \mathrm{AgNO}_{3}$ and $8.8 \mathrm{~g} / \mathrm{L}$ phytagel with appropriate selection agents).

6) Sub-culture the leaf discs on selection medium every 2 weeks until resistant buds were obtained.

7) The resistant buds were transferred to MS0 rooting medium to form roots; afterwards, the resulted plants were then transferred to soil.

\section{Discussion}

Leaf disc method is the widely used method for the genetic transformation of tobacco. This process is affected by many factors. In order to establish an efficient leaf disc transformation system of N.benthamiana, we analyzed and optimized different affecting factors and obtained better parameters for the process.

The leaf disc transformation method is usually consisted of several steps, namely, pre-cultivation, co-cultivation, selection and the later on regeneration. Among them, inhibition of Agrobacterium growth is an important issue in selection medium. We found that lower temperature, $18^{\circ} \mathrm{C}$, is as efficient as higher temperature, $25^{\circ} \mathrm{C}$, for co-cultivation step. Both temperatures give good transient transformation frequency. Considering the slow growth of Agrobacterium at lower temperature, it is obviously conducive to the next selection step. On the premise of pre-cultivation at $18^{\circ} \mathrm{C}$, we optimized the other parameters of the whole process. We found, the best pre-cultivation time is for one day, the best co-cultivation time is for 3 days. Under the above conditions, the best agrobacterium concentration for transformation is at $O D_{600} \approx 1$.

Studies have shown that $\mathrm{AgNO}_{3}$ not only promotes organogenesis, but also promotes somatic embryogenesis (Zhang et al., 1997). When the concentration of $\mathrm{AgNO}_{3}$ was $1.0 \sim 5.0 \mathrm{mg} / \mathrm{L}$, it could promote the differentiation of tobacco regeneration buds (Wang et al., 2006). We studied the effects of four concentrations of $\mathrm{AgNO}_{3}$ on the buds induction of N.benthamiana. The results showed that when the concentration of $\mathrm{AgNO}_{3}$ was $4.5 \mathrm{mg} / \mathrm{L}$, the buds induction rate was as high as $68.06 \%$. One the other hand, the hardness of medium had a significant effect on the regeneration of many plants. We found that when the phytagel concentration of the regeneration medium was $9 \mathrm{~g} / \mathrm{L}$, regeneration rate of N.benthamiana is around $77.78 \%$.

Since $\mathrm{AgNO}_{3}$ alone or high concentration of phytagel itself, both can significantly increase the regeneration frequency of N.benthamiana. We hypothesized that combination use of the two may have a better effect. According to results of the single factor experiments, we used the $4.5 \mathrm{mg} / \mathrm{L} \mathrm{AgNO}_{3}$ and $9 \mathrm{~g} / \mathrm{L}$ phytagel as the center combination, employing CCD to design the response surface and carried out the experiments. We found that the combination of $4.3 \mathrm{mg} / \mathrm{L} \mathrm{AgNO}_{3}$ and $8.8 \mathrm{~g} / \mathrm{L}$ plant gel was the best combination in theory. Finally, we confirmed the theoretical values with experiments. In the end, we summarized our optimized leaf-disc transformation process of N.benthamiana. 
Plant Gene and Trait 2020, Vol.11, No.12, 1-10

http://genbreedpublisher.com/index.php/pgt

\section{Materials and Methods}

\subsection{Materials}

The MS medium is lab made according classical references. Both 6-BA and NAA are from Hefei Bomei biological company; $\mathrm{AgNO}_{3}$ is from Suzhou Tian Ke company, and the phytagel is produced by EKEAR Biotech Corp, Shanghai. The N.benthamiana seeds Agrobacterium tumefaciens GV3101 containing plasmid vector pCambia1305.1 was from stock of our own laboratory.

\subsection{Methods}

3.2.1 Optimization of N.benthamiana leaf disc transformation conditions

Pre-cultivation medium is the classical MS medium with $\mathrm{pH} 5.8$; co-cultivation medium: $\mathrm{MS}+(1 \mathrm{mg} / \mathrm{L}$ 6-BA $)+(0.1 \mathrm{mg} / \mathrm{l} \mathrm{NAA})+(0.3 \%$ sucrose $), \mathrm{pH} 5.8$; Selection medium: MS $+(1 \mathrm{mg} / \mathrm{L}$ 6-BA $)+(0.1 \mathrm{mg} / \mathrm{l} \mathrm{NAA})+(400$ $\mathrm{mg} / \mathrm{L} \mathrm{Cef})+(0.3 \%$ sucrose $), \mathrm{pH} 5.8$. Transformation of E.coli, preparation of plasmid, and Agrobacterium tumefaciens GV3101-pCambia1305.1 was obtained by existing methods in the laboratory (Huang et al., 2017).

In the experiment, different co-cultivation temperatures was tested, namely they are $18^{\circ} \mathrm{C}, 21^{\circ} \mathrm{C}, 25^{\circ} \mathrm{C}$ and $28^{\circ} \mathrm{C}$; Test co-cultivation time was for 1 day, 2 days and 3 days, with 14 16 explants in each group, three replicates; the pre-cultivation time was for 0day, 1day, 2days and 3days; 16 explants in each group, and were repeated three times; Agrobacterium tumefaciens GV3101-pCAMBIA1305.1 was cultured in shaker to $O D_{600} \approx 0.5$, after centrifugation, re-suspended in liquid MS medium, to $O D_{600} \approx 0.3$. Leaves after pre-cultivation were immersed in the bacterial solution for 5 7 minutes, then the excess liquid drained off with filter paper, and then transferred to co-cultivation medium. Eventually, the co-cultivated leaf-discs were placed on the medium containing Cef ${ }^{\mathrm{T}} .400$ $\mathrm{mg} / \mathrm{L}$ for bacterium resistance experiment.

\subsubsection{Optimization of concentrations of $\mathrm{AgNO}_{3}$ and Phytagel}

Using MS ( $1 \mathrm{mg} / \mathrm{L} 6-\mathrm{BA}+0.1 \mathrm{mg} / \mathrm{L}$ NAA $+0.3 \%$ sucrose $+5 \mathrm{~g} / \mathrm{L}$ phytagel $)$ as the basic medium, the true leaves of sterile N.benthamiana plants, of 50 days after germination, were cut into $5 \mathrm{~mm} \times 5 \mathrm{~mm}$ leaves and pre-cultivated for 3 days at $20^{\circ} \mathrm{C}$. The leaves were sub-cultured on the medium containing $\mathrm{MS}(1 \mathrm{mg} / \mathrm{L} 6-\mathrm{BA}+0.1 \mathrm{mg} / \mathrm{L}$ $\mathrm{NAA}+0.3 \%$ sucrose $+5 \mathrm{~g} / \mathrm{L}$ phytagel) to induce callus and subculture every 2 weeks.

The concentration of $\mathrm{AgNO}_{3}$ was $0,1.5 \mathrm{mg} / \mathrm{L}, 3 \mathrm{mg} / \mathrm{L}, 4 \mathrm{mg} / \mathrm{L}$ and $6 \mathrm{mg} / \mathrm{L}$. The phytagel concentration was $0.5 \%$, $0.7 \%, 0.9 \%$ and $1 \%$ respectively. There were 6 pieces of callus in each bottle, 4 bottles in each group, and repeated three times.

Optimized $\mathrm{AgNO}_{3}$ and phytagel concentrations were chosen, the software Design expert 10 was used to design the test plan of CCD (Central composite design) model, and the corresponding response value was obtained according to the test plan, and the regression analysis of the two factors was done by fitting the response surface multiple regression, and the theoretical value of optimized tobacco regeneration frequency was obtained, and the verification test was carried out accordingly.

\section{Authors' contributions}

HQ and ZXL perceived and designed the experiments. The experiments were carried out mainly by ZXL and DZJ, WYY and DXJ participated in the response surface test, XXBand SWW participated DZJ ong's experiments, ZZ and ZQQ helped ZXL with his parts. ZXL and DZJ analyzed the data, ZXL wrote the first draft. HQ and CXS guided the data analysis, MS writing and editing. All authors read and approved the final manuscript.

\section{Acknowledgements}

The authors thank Natural Science Foundation of Shandong Province, China (Project. No. ZR2014CM001), the opening grant of State Key Laboratory of Crop Biology, Shandong Agricultural University, China (Fund No. 2018KF03) and the Scientific Research start-up Fund of the Ministry of Education of Chian (2015).

\section{References}

Cao L.X., Zhao P., Tang Y.L., and Zhu C., 2001, Stimulation effect of silver nitrate on shoot regeneration in cotyledon tissue culture of cucumber, Journal of Gansu Agricultral University, (2): 168-171 
Du H.W., Xu F.X., Huang M., Zhao Q.G., and Zhang Z.X., 2008, Effect of silver nitrate on tissue culture of maize immature embryo, Hebei Agricultural Sciences, (8): 62-63

Du H., Zhuang D.H., and Huang W.H., 2000, Stimulation effect of silver nitrate on shoot regeneration in cotyledon tissue culture of Brassia campestris, Journal of Tropical Subtropical Botany, (2): 109-112

Eapen S., and George L., 1997, Plant regeneration from peduncle segments of oil seed Brassica species: influence of silver nitrate and silver thiosulfate, Plant Cell Tiss Org., 51:229 232

Huang X.J., Zhang J.D., Zhang Z., Li Y.J., Cao X.S. and Hu Q.A., 2017, An optimized method for preparation and transformation of Escherichia coli competent cells, Genomics and Applied Biology, 36(12): 5199-5204

Mookkan M., and Andy G., 2014, AgNO3 boosted high-frequency shoot regeneration in Vigna mungo (L.) Hepper, Plant signaling \&amp; behavior, 9(10) https://doi.org/10.4161/psb.32165 PMid:25482817 PMCid:PMC4622596

Nail S.K., and Chand P.K., 2003, Silver nitrate and amino ethoxy vinylglycine promote in vitro adventitious shoot regeneration of pomegranate (Punica granatum L.), J. Plant Physiol, 160: 423-430

https://doi.org/10.1078/0176-1617-00949

PMid:12756923

Pestana M.C., Lacorte C., De Freitas V.G., Oliveira D.E., and Mansur E., 1999, In vitro regeneration of peanut (Arachishypogaea L) through organogenesis: Effect of culture temperature and silver nitrate, In Vitro Cell Dev. Biol. Plant, 35: 214-216 https://doi.org/10.1007/s11627-999-0080-3

Qin Y.H., Zhang S.L., Hu G.B., Zhang X.Y., 2006, Effects of different AgNO3 levels on the growth and activities of antioxidant enzymes in strawberry in vitro, Journal of Fruit Science, (05): 715-719

Wang L., and Zhou J., 2000, Effects of hormone ratio and medium hardness on the rooting of tissue culture seedlings of Populus alba, Tibet Science and Technology, (05): 67-68+73

Wang W.X., Qu S., Cao C.Y., and Xu S.K., 2006, Effect of Silver Nitrate on Callus Formation and Bud Regeneration of Tobacco (Nicotiana tabacum L.) leaf in vitro and changes in their proline and malondialdehyde contents, Plant Physiological Communications, (4): 668-670

Wang D.X., Peng D., and Zhang S., 2018, Advances in genetic transformation of woody plants mediated by Agrobacterium tumefaciens, Northern Horticulture, No. 401187-191

Zhao M.Z., Wang Z.W., Wu W.M., Qian Y.M., and Yuan J., 2007, Effects of Macro -element, Sucrose and Agar in Medium on growth of Strawberry Plantlet in vitro, Journal of Jiangsu Agricultal Science, (6): 626-629

Zhai Y., Zhang Z.Q., and Song X.D, 2010, Effects of different concentrations of agar on bulbils propagation of tissue cultured lily 'Siberia', Northern Horticulture, (6): 159-161

Zhang P., Fu A.G., and Wang A.G., 1997, Role and Possible Machanism of AgNO 3 in Plant Culure in vitro, Plant Physiological communications, (5): 376-379 